\title{
TRATAMENTO TÓPICO DO LIQUEN PLANO GENGIVAL COM CLOBETASOL $0,05 \%$.
}

Clovis TORQUATO NETO, Luciana Reis AZEVEDO-ALANIS, Antonio Adilson Soares de LIMA, Cintia Milani CONTAR, Maria Ângela Naval MACHADO

O líquen plano é uma doença mucocutânea crônica, autoimune, de etiologia incerta, prevalente em mulheres entre 30-60 anos de idade. O líquen plano gengival (LPG) pode se apresentar na forma reticular, erosiva ou atrófica. O LPG persiste por vários anos com períodos de exacerbação (dor e sensibilidade) e quiescência (assintomáticos). O objetivo deste trabalho é apresentar dois casos clínicos de LPG tratados topicamente com gel de propionato de clobetasol. Ao exame clínico intrabucal observou-se que os pacientes apresentavam lesões atróficas e erosivas bilaterais localizadas na gengiva inserida. Foi realizada a biopsia incisional e o exame histológico confirmou o diagnóstico de LPG erosivo e atrófico. Os pacientes foram tratados com gel de propionato de clobetasol a 0,05\% tópico, colocado em moldeira de acetato e mantido em contato com a gengiva durante 15 minutos, três vezes ao dia. Um mês após o tratamento os pacientes apresentaram uma melhora clínica visível da gengiva e redução da dor. Pacientes submetidos ao tratamento utilizam a medicação tópica em períodos de exacerbação da doença. Conclui-se que o uso tópico do gel de clobetasol a 0,05\% em moldeira é eficaz no tratamento do líquen plano gengival.

Palavras-chave: Líquen Plano; Clobetasol; Terapia Combinada 